Kate L. Brown

Graeme MacLaren

Bradley S. Marino

\section{Looking beyond survival rates: neurological outcomes after extracorporeal life support}

Received: 23 July 2013

Accepted: 25 July 2013

Published online: 14 August 2013

(C) Springer-Verlag Berlin Heidelberg and ESICM 2013

\section{K. L. Brown $(\bowtie)$}

Cardiac Unit, Great Ormond Street Hospital for Children NHS Foundation Trust and Institute for Cardiovascular Science, University College London, Great Ormond Street, London WC1N 3JH, UK

e-mail: katherine.brown@gosh.nhs.uk

Tel.: +44-207-8138180

Fax: +44-207-8298673

\section{G. MacLaren}

Cardiothoracic ICU, National University Hospital, 5 Lower Kent Ridge Rd, Singapore 119074, Singapore

e-mail: gmaclaren@iinet.net.au

Tel.: +6567725275

G. MacLaren

Department of Paediatrics, University of Melbourne, Melbourne, Australia

G. MacLaren

Paediatric Intensive Care Unit, Royal Children's Hospital,

Melbourne, Australia

\section{B. S. Marino}

Cardiac Intensive Care Unit, Divisions of Cardiology and Critical Care Medicine at Cincinnati Children's Hospital Medical Center and Heart Institute, University of Cincinnati College of Medicine Cincinnati, MLC 50503333 Burnet Avenue, Cincinnati, OH, USA e-mail: bradley.marino@cchmc.org

Tel.: +1-513-8031705

Fax: +1-513-8030370
Extracorporeal membrane oxygenation (ECMO) has been used since the 1970s to rescue the sickest of children with cardiopulmonary failure that are refractory to conventional intensive care therapies $[1,2]$. As was shown in the UK randomized trial of ECMO for neonatal respiratory failure, patients requiring ECMO are at high risk of neurological injury [3]. In the current era, with improving survival rates for critically ill children and an expansion in the role of ECMO to include patients in cardiac arrest (ECPR, extracorporeal cardiopulmonary resuscitation) [4], there is growing awareness that it is inadequate to focus solely on short-term survival. Due to the neurologic morbidities associated with ECMO support, longer term outcomes including physical, neurodevelopmental, and psychosocial outcomes need to be monitored and carefully evaluated to optimize quality of life [5].

In a recent issue of Intensive Care Medicine, two studies were published that deepen our understanding of longer term outcomes after ECMO.

Polito and colleagues present a report of risk factors for neurological injury in neonates undergoing ECMO based on the ECMO registry of the Extracorporeal Life Support Organization (ELSO) [6]. Of 7,190 neonates included in the Polito study, 1,412 (20\%) experienced a neurological complication, these being more likely in the smallest and sickest babies. Given that the Polito study is based on ELSO data captured within the intensive care unit where evaluation of neurodevelopmental outcome has inevitable limitations related to systemic illness and the use of sedatives, and that $62 \%$ of patients with neurological complications died, this is likely to represent the worst end of the spectrum. Birth weight $<3 \mathrm{~kg}$, gestational age $<36$ weeks, need for cardiopulmonary resuscitation 
prior to ECMO, pre-ECMO blood $\mathrm{pH} \leq 7.11$, pre-ECMO bicarbonate use, prior ECMO exposure, and use of venoarterial ECMO were associated with a higher risk of neurologic complications. While some of these predictors of worse neurologic outcome are not amenable to intervention (e.g., birth weight and gestational age), those that are modifiable should be targeted for future intervention to minimize future neurologic injury in the high-risk neonatal ECMO population.

Madderom and a multidisciplinary team of colleagues [7] from the neurodevelopmental follow-up clinic at Erasmus University report their experience with neonatal respiratory ECMO survivors to age 8 years. Of 135 children evaluated, $91 \%$ were in mainstream school, $39 \%$ of the cohort required educational support, and $9 \%$ were in special education. Although intelligence fell within the normal range for the population, children treated with ECMO in the past were more likely than their peers to experience problems executing their schoolwork and to have emotional and/or behavioral issues. Specifically, the Dutch cohort by parent and teacher report demonstrated both internalizing (i.e., somatic complaints) and externalizing (i.e., aggression) behaviors, as well as issues with attention, thought, total problems, and social cognition. This phenotype is similar to that seen in child and adolescent complex congenital heart disease survivors who have undergone cardiopulmonary bypass as neonates in both the US and UK, which may significantly affect quality of life $[8,9]$. This study offers some unique insights into the types of impairment children of school age who have survived ECMO may experience and therefore the support that they may require in future life.

A registry such as ELSO [10], which has wide coverage and a large number of patients, can offer objective data on risk factors for short-term outcome measures and is invaluable for answering research questions or for generating hypotheses for future mechanistic or intervention studies. It also offers unique and vital opportunities to benchmark outcomes, which is particularly important for such a high-risk and resource-intense treatment as ECMO. However, registry data have inherent limitations, and it is vital to complement these short-term data with detailed longitudinal assessment of outcomes including the kind of prospective follow-up of survivors reported in the Madderom study and others [11, 12].

Mechanisms of injury to the developing brain in children undergoing treatment with ECMO are both primary (including congenital syndromes or vascular malformations) and secondary, related to both the underlying disease process and aspects of ECMO support itself (including hypoxic-ischaemic encephalopathy, reperfusion injury, raised intracranial pressure, low cerebral blood flow states including cardiac arrest, cerebral bleeding, disordered cerebral autoregulation, thromboembolism and instrumentation of the cerebral vessels). Polito and colleagues allude to disorders of cerebral autoregulation being implicated in the evolution of severe neurological complications during ECMO in neonates. Observational data support the theory that cerebral autoregulation may be disordered during neonatal ECMO support [13]. Greater understanding of the mechanisms of neurological injury in the intensive care unit may lead to beneficial changes in practice-for example, cooling for perinatal asphyxia [14] —although the benefits of cooling to reduce neurological injury in ECMO-treated neonates have not been well established [15]. Further exploration of cerebral autoregulation and how it is affected by both critical illness and ECMO may represent a fruitful avenue of future research.

Retrospective evaluations of various single-center cohorts from the USA [16-18], Canada [19], Australia [20], and the UK [21] shed further light on longer term outcomes in regards to late mortality events [21], neurodevelopmental deficits [12, 17, 19], and quality of life $[18,20]$ in neonates and children who survive to hospital discharge following ECMO. All these various data show it is essential for ECMO clinicians to invest in the followup of their patients so that patient-specific interventions can be put in place to optimize functional survival. Indeed, this has been recommended by several professional societies including the American Heart Association (AHA) [22], the Pediatric Cardiac Intensive Care Society (PCICS) [23, 24] and ELSO [25].

In conclusion, Polito, Madderom and co-workers have contributed important studies that take us forward toward a greater understanding of neurodevelopmental outcomes in ECMO patients. This represents an area that intensive care clinicians and tertiary hospitals managing children on ECMO will be required to attend to more closely in coming years. The critically ill children that undergo ECMO, their families and the local services caring for them all deserve a renewed focus on this aspect of their care. Future goals must include a greater mechanistic understanding leading to reduced levels of neurodevelopmental injury in ECMO patients and the initiation of innovative, scalable, long-term intervention protocols to meet the needs of this high-risk population. 
Conflicts of interest The authors declare no conflicts of interest.

\section{References}

1. Bartlett RH, Gazzaniga AB, Huxtable RF, Schippers HC, O'Connor MJ, Jefferies MR (1977) Extracorporeal circulation (ECMO) in neonatal respiratory failure. $\mathrm{J}$ Thorac Cardiovasc Surg 74(6):826-833 (Epub 1977/12/01)

2. Bartlett RH, Gazzaniga AB, Toomasian J, Coran AG, Roloff D, Rucker R (1986) Extracorporeal membrane oxygenation (ECMO) in neonatal respiratory failure. 100 cases. Ann Surg 204(3):236-245 (Epub 1986/09/01)

3. UK collaborative randomised trial of neonatal extracorporeal membrane oxygenation (1996) UK Collaborative ECMO Trail Group. Lancet 348(9020):75-82 (Epub 1996/07/13)

4. Thiagarajan RR, Laussen PC, Rycus PT, Bartlett RH, Bratton SL (2007) Extracorporeal membrane oxygenation to aid cardiopulmonary resuscitation in infants and children. Circulation 116(15):1693-1700 (Epub 2007/09/26)

5. Marino B, Uzark K, Ittenbach R, Drotar D (2010) Evaluation of quality of life in children with heart disease. Prog Pediatr Cardiol 29:131-138

6. Polito A, Barrett CS, Wypij D, Rycus P, Netto R, Cogo P et al (2013) Neurologic complications in neonates supported with extracorporeal membrane oxygenation. An analysis of ELSO registry data. Intensive Care Med. doi: 10.1007/s00134-013-2985-x

7. Madderom MJ, Reuser J, Utens EM, van Rosmalen J, Raets M, Govaert P et al (2013) Neurodevelopmental, educational and behavioural outcome at 8 years after neonatal ECMO: a nationwide multicenter study. Intensive Care Med. doi:

10.1007/s00134-013-2973-1

8. Marino BS, Drotar D, Cassedy A, Davis R, Tomlinson RS, Mellion K et al (2011) External validity of the pediatric cardiac quality of life inventory. Qual Life Res 20(2):205-214 (Epub 2010/12/29)

9. Wray J, Franklin R, Brown K, Cassedy A, Marino BS (2013) Testing the pediatric cardiac quality of life inventory in the United Kingdom. Acta Paediatr 102(2):e68-e73 (Epub 2012/11/27)

10. ELSO (2013) Registry of the Extracorporeal Life Support Organisation. Ann Arbor, MI
11. McNally H, Bennett CC, Elbourne D, Field DJ (2006) United Kingdom collaborative randomized trial of neonatal extracorporeal membrane oxygenation: follow-up to age 7 years. Pediatrics 117(5):e845-e854 (Epub 2006/04/26)

12. Bennett CC, Johnson A, Field DJ, Elbourne D (2001) UK collaborative randomised trial of neonatal extracorporeal membrane oxygenation: follow-up to age 4 years. Lancet 357(9262):1094-1096 (Epub 2001/04/12)

13. Papademetriou MD, Tachtsidis I, Elliot MJ, Hoskote A, Elwell CE (2012) Multichannel near infrared spectroscopy indicates regional variations in cerebral autoregulation in infants supported on extracorporeal membrane oxygenation. J Biomed Opt 17(6):067008 (Epub 2012/06/28)

14. Azzopardi DV, Strohm B, Edwards AD, Dyet L, Halliday HL, Juszczak E et al (2009) Moderate hypothermia to treat perinatal asphyxial encephalopathy. N Engl J Med 361(14):1349-1358 (Epub 2009/10/03)

15. Field DJ, Firmin R, Azzopardi DV, Cowan F, Juszczak E, Brocklehurst P (2010) Neonatal ECMO study of temperature (NEST)-a randomised controlled trial. BMC Pediatr 10:24 (Epub 2010/04/21)

16. Hamrick SE, Gremmels DB, Keet CA, Leonard CH, Connell JK, Hawgood S et al (2003) Neurodevelopmental outcome of infants supported with extracorporeal membrane oxygenation after cardiac surgery. Pediatrics 111(6 Pt 1):e671-e675 (Epub 2003/06/05)

17. Glass P, Bulas DI, Wagner AE, Rajasingham SR, Civitello LA, Papero $\mathrm{PH}$ et al (1997) Severity of brain injury following neonatal extracorporeal membrane oxygenation and outcome at age 5 years. Dev Med Child Neurol 39(7):441-448 (Epub 1997/07/01)

18. Costello JM, O’Brien M, Wypij D, Shubert J, Salvin JW, Newburger JW, Laussen PC, Arnold JH, FynnThompson F, Thiagarajan RR (2012) Quality of life of pediatric cardiac patients who previously required extracorporeal membrane oxygenation. Pediatr Crit Care Med 13(4):428-434
19. Lequier L, Joffe AR, Robertson CM, Dinu IA, Wongswadiwat Y, Anton NR et al (2008) Two-year survival, mental, and motor outcomes after cardiac extracorporeal life support at less than five years of age. J Thorac Cardiovasc Surg 136(4):976-983.e3 (Epub 2008/10/29)

20. Taylor A, Butt W, Ciardulli M (2003) The functional outcome and quality of life of children after admission to an intensive care unit. Intensive Care Med 29(5):795-800

21. Iguchi A, Ridout DA, Galan S, Bodlani C, Squire K, O'Callaghan $\mathrm{M}$ et al (2013) Long-term survival outcomes and causes of late death in neonates, infants, and children treated with extracorporeal life support*. Pediatr Crit Care Med 14(6):580-586 (Epub 2013/07/05)

22. Marino BS, Lipkin PH, Newburger JW, Peacock G, Gerdes M, Gaynor JW et al (2012) Neurodevelopmental outcomes in children with congenital heart disease: evaluation and management: a scientific statement from the American Heart Association. Circulation 126(9):1143-1172 (Epub 2012/08/02)

23. MacLaren G, Dodge-Khatami A, Dalton H (2013) Pediatric Cardiac Intensive Care Society and Extracorporeal Life Support Organization joint statement on mechanical circulatory support in children: a consensus review. Pediatr Crit Care Med 14:S1-S2

24. Brown KL, Ichord R, Marino BS, Thiagarajan RR (2013) Outcomes following extracorporeal membrane oxygenation in children with heart disease. Pediatr Crit Care Med 14:S73S83

25. Extracorporeal Life Support Organization: ELSO recommendations for neonatal-pediatric ECMO patient follow-up. (2013) Available at: http://www.elsonet.org/index.php/ resources/guidelines.html Accessed 19 July 2013 